\title{
Pharmaceutical pricing conundrum: time to get rid of it?
}

\author{
Livio Garattini ${ }^{1} \cdot$ Anna Padula $^{1}$
}

Published online: 20 July 2018

c) Springer-Verlag GmbH Germany, part of Springer Nature 2018

\section{Introduction}

A basic concept of economics is that a price stems from the intersection between supply and demand curves in any common market. However, there are markets where consumers do not pay for goods directly, like in healthcare, and prescription drugs are a well-known example. Not by chance called 'ethical drugs', their importance for patients' health makes them 'merit goods' regulated beyond the common laws of the market [1]. Ethical drugs are mostly prescribed by physicians to patients and funded by public expenditure in highly developed countries, such as Western European ones, characterized by well-established welfare systems. Accordingly, price regulation schemes have long been an unavoidable policy response to control public pharmaceutical expenditure [2].

On the supply side, the pharmaceutical industry is nowadays predominantly private and multinational, with the negotiation of high prices considered a success in all countries, crucial for maximizing worldwide profits and pushing up the value of stocks and shares [3]. However, the present era of austerity in public funding has made resources really scarce, leading to little growth of pharmaceutical expenditures in many countries, including the wealthier ones.

Here, focusing on Western European countries, we summarize the pharmaceutical pricing background, then discuss the main issues currently debated, and finally depict a radically alternative scenario, mainly oriented more to pharmaceutical budgeting than pricing.

Livio Garattini

livio.garattini@marionegri.it

1 CESAV, Centre for Health Economics, IRCCS Institute for Pharmacological Research "Mario Negri", 24020 Ranica, Italy

\section{European background}

The regulation of pharmaceutical prices has a long tradition in Western European countries and various solutions have been attempted in recent decades [4]. In the very first attempts, in large countries like France, Italy and Spain, prices were set on the basis of the main cost items borne by the pharmaceutical industry (e.g., manufacturing, marketing, research). These schemes were progressively abandoned, mainly because the domestic cost estimates at the onset of "multinationals' era" were too uncertain. Delocalization and globalization are also the main reasons for the crisis of the existing British scheme- the Pharmaceutical Price Regulation Scheme (PPRS) - which acts on the domestic profitability of each pharmaceutical firm [2], without setting drug prices despite its name.

An approach based on grouping similar drugs was introduced in Germany in the late 1990s, then adopted in the Netherlands and is now applied in various forms in many European countries. It consists of setting the same 'reference price' for reimbursement to products considered therapeutically overlapping, based on either the domestic prices ('internal') or the foreign ones ('external') of already marketed products. Along with the often difficult decision on where to 'draw the line' around a reference group for different active substances [2], the sensible strategy of clustering products of similar efficacy under the same price suffers two practical limits for widespread application. The first is implicit in the concept, since it requires the availability of domestic and/or foreign prices for already marketed similar drugs. The second is a consequence of the current uncertainty on many real prices both at national and international levels (see below).

A third potential approach for pricing new and innovative drugs (thus complementary to the previous one) is to 'monetize' their therapeutic 'added value' on the basis of economic models populated by short-term efficacy data and long-term cost estimates [2]. Announced some years ago in the UK, the value-based approach is a form of extension of reimbursement criteria based on multidisciplinary health 
technology assessment (HTA) [5], with the drug price being the unknown in the economic model. Thus, it suffers all the intrinsic limits of HTAs [6], further stressed by the need to use many uncertain estimates and doubtful assumptions for new drugs at market approval. In the end it may appear as much an art as a science [7].

Finally, a straightforward approach to exploit the purchasing power of health authorities to the full is competitive tendering. Recently extended from hospital services to community care in a few countries (e.g., Germany and the Netherlands) [1], bids have to be designed in such a way that price competition can produce its effects [8]. Accordingly, many manufacturers should be able to tender and lots should include many products. Beyond the issue mentioned for reference pricing on where to draw the line for bidding similar drugs, two closely related drawbacks can arise with tendering. First, a few big companies could drastically cut prices, so as to push most competitors out of the market and gain dominant positions, with subsequently raised prices for themselves in the long run. Second, 'losers' are very likely to raise legal questions when big lots are tendered and the turnover is substantial. This is also why public tenders are still limited mainly to off-patent drugs in most European countries.

At present, the leading tendency for pricing in Europe is direct negotiation with the pharmaceutical industry [2]. Many domestic authorities strive for savings through price caps, expenditure ceilings, paybacks and confidential discounts. Some countries (e.g., Belgium, Luxembourg and the Netherlands) are even trying to increase their domestic purchasing power by getting together to negotiate prices with pharmaceutical companies [9]. All these strategies are administratively burdensome, possibly with costs even offsetting savings $[10,11]$. Moreover, they can lead to different real prices for the same drug in the same country, making international price comparisons a puzzle. Finally, since any trade negotiation implies some confidentiality if it is to be effective and thus lacks transparency by definition, it is also hard to assess whether countries exploit their different purchasing powers to the best.

\section{Discussion}

Pharmaceutical expenditure, like anything else, is determined by two factors: prices and volumes. While nowadays the latter is easier for health authorities to monitor, using big databases, and-it is to be hoped-can be made more appropriate to patients' needs thanks to the work of health professionals [12], the former seems to be increasingly out of control in a 'market failure' situation like pharmaceuticals $[9,13]$. Prices are the correct means to match demand with supply only when there is scope for competition. When prices are set for many products through (unavoidably) arbitrary decisions, the result is a distortion of relative prices and thus irrational allocation of financial resources [14]. This happens today in most developed countries for pharmaceutical expenditures, with Europe being no exception.

On the demand side, the main goal of health authorities in highly developed countries is universal access to essential drugs, and possibly prompt access to new ones too [9]. On the supply side, the obvious goal of the pharmaceutical industry is to legally maximize profits through turnover, so as to guarantee high returns on investments [15]. In particular, companies are keen to maximize profits with similar prices across countries [9], to discourage parallel imports.

The advocates for the pharmaceutical industry claim that high prices are needed to support the enormous expense of researching and developing new drugs [16]; critics argue that the present huge profits can no longer be justified in the long run, since too many new drugs are launched with skyhigh prices, untenable even in high-income countries [17]. The pro-industry argument seems harder to accept in the light of the increasing shift by big companies from in-house development of new drugs to acquisition of small start-ups $[9,18]$. This eventually shifts the risk from industry having to invest mainly on drug development, to governments and investors backing basic research. Not by chance, the published cost estimates for developing a new drug vary almost ten times from the lowest to the highest [19]. Then, aggressive marketing is still required to sell expensive medicines that often differ only marginally $[18,20]$, with trendy 'personalized medicine' helping to create an ideal setting for price discrimination for new similar drugs [21]. Anticancer drugs can be considered an emblematic example of unsustainable prices [22]. Because of the emotive nature of cancer, health authorities find it hard to resist 'pleas' for reimbursement of new drugs, even when their efficacy is still marginal [13]. So, pharmaceutical companies have a clear incentive to invest in these drugs and health authorities spend an increasing share of pharmaceutical expenditure on very expensive end-of-life treatments, regardless of their low impact on survival (a few extra months at best) and quality of life (very severe side effects, without much relief of symptoms in life's final phases) [13, 15]. The typical marketing strategy of anti-cancer drugs is to launch them for late stage disease, with less demanding and shorter trials, then extending the indications to earlier stages [9]. Finally, since anti-cancer therapies are often more effective in combination, most new drugs result in a massive add-on cost.

Last but not least, sudden drug shortages and substantial price increases have been recently recorded even for many generics after company mergers and acquisitions [23], further undermining the broad reputation of the pharmaceutical industry. 


\section{Alternative scenario}

Here we envisage a radically different scenario for pharmaceutical pricing in European countries, to (re)establish an acceptable trade-off between public and private interests.

As discussed in previous commentaries [1], we believe that pharmaceutical policy needs drastic changes, beginning from the start of a drug's life-cycle. First, a specific European agency for health products could be introduced to constrain the 'jungle' of pharmaceutical patents [3]. At present, the single national offices do not have knowledge of pharmaceuticals, by definition, and the European Patent Office (EPO) is a big executive body in no way legally bound to the EU and entirely funded by patent fees, thus totally out of control in a health perspective. The excess of discretion by the pharmaceutical industry in filing patents often generates an 'invention cascade' of patents even on the same drug, giving rise to many costly litigations, eventually a waste of money indirectly funded by pharmaceutical expenditures. Second, the regulatory tasks of the European Medicines Agency (EMA) should be expanded far beyond the present scope of preliminary assessments of efficacy and safety of new drugs [24], to cover their therapeutic 'added value' compared to already existing therapies before market approval, thus making reimbursement policies more rational and homogeneous at national level.

After having decided what drugs are eligible for reimbursement according to their absolute and relative efficacy, their pricing could be drastically simplified by calculating unit costs for all prescribed drugs. First, reimbursable drugs could be classified in a limited number of therapeutic classes according to their indications. ${ }^{1}$ Second, the first year's budget could roughly coincide with the historical expenditure of the previous year for each therapeutic class, to avoid any start-up shock; then smooth changes could be introduced by national authorities on a yearly basis, taking account of future drug listing/delisting and inflation/deflation. Third, the listed drugs could be further classified by patent protection (off-/on-patent) and manufacturing procedure (chemical/biological), to differentiate the unit costs reimbursed for each therapeutic class. ${ }^{2}$ These two criteria are the only ones that can be objectively applied for differentiating the drugs'

\footnotetext{
${ }^{1}$ For instance, 18 therapeutic classes could be set, based on the first level of the ICD and matched with the first level of the ATC classification.

${ }^{2}$ For instance, a $50 \%$ decrease after patent expiry could be reasonable for patenting, while manufacturing would require a survey to estimate an average difference for the two types of drugs. Assuming a hypothetical difference of $+20 \%$ for manufacturing biologics, the other three weights would range from 0.5 for a chemical generic to 1.2 for an on-patent biologic, with an intermediate value of 0.6 for biosimilars.
}

unit costs for reimbursement. Fourth, national authorities could reimburse pharmaceutical companies for all the defined daily doses prescribed, and their unit costs could be modified during the year, to respect the budget if the final volumes vary substantially from those initially budgeted. ${ }^{3}$

Finally, health authorities could pay community pharmacies a fee-for-service per prescription at the end of the pharmaceutical chain, to recognize the public service provided, while pharmaceutical companies would be free to trade distribution margins with private wholesalers, as has happened for decades in countries like the NL and the UK [25].

\section{Comment}

Pharmaceutical pricing has become increasingly challenging and politically unsustainable even in high-income European countries [26]. Although industry argues (not without reason) that health authorities could save huge amounts of money through spending reviews in other healthcare services (e.g., hospitals) [9], rather than cutting pharmaceutical prices, this aim should not be considered an alternative to efficient pharmaceutical policy. Wastes in other health expenditure budgets do not justify double-digit profit margins of pharmaceutical firms, conversely mirrored by the scarcity (even absence) of bankruptcies. While the pharmaceutical industry has always been ready to adapt promptly to new market scenarios, health authorities still have difficulty steering companies' marketing strategies to play their role of 'third-party payers' better.

Unlike some authors $[9,26]$, we think that sensible strategies, like reference pricing and incentives for health professionals to control prescriptions, are not enough to change direction. Yet, more recent strategies, such as value-based pricing and outcome-based agreements, have already demonstrated insurmountable limits [10,11], while full transparency of pharmaceutical costs is not achievable and that of prices not necessarily effective. To keep pharmaceutical expenditures under control and restore the fragile balance between public objectives of health authorities and private incentives of pharmaceutical industry, we are convinced that the pricing 'conundrum' needs to be tackled urgently with radical but also defensible and relatively easy-to-manage solutions. The underlying rationale of our proposal to stop setting arbitrary prices is the drastic reduction of their impact on pharmaceutical expenditures. Prices can hardly (if ever) be really right in a 'market failure' context, so their

\footnotetext{
${ }_{3}^{3}$ For instance, national authorities could reimburse pharmaceutical firms on a monthly basis, applying the unit costs of each therapeutic class weighed for the four types of products (see previous footnote), and the unit costs per dose should be proportionally decreased/ increased every quarter.
} 
effect must be minimized, to limit the distortion of allocation of resources in pharmaceuticals, from upstream research investments to downstream health expenditures.

Assuming that all reimbursable drugs are equally essential for the population's health, including those that contribute to making life-threatening diseases chronic for years, and regardless of their dates of approval, rational budgeting should be given priority over irrational pricing, hopefully boosting drug consumption only related to health needs. Accordingly, the reimbursement of all prescribed ethical drugs through a limited number of standard unit costs per dose need not be considered necessarily taboo. Here we put forward a general proposal to stimulate debate on the question.

Funding No sources of funding were used to conduct this study or prepare this manuscript.

\section{Compliance with ethical standards}

Conflict of interest Anna Padula and Livio Garattini have no conflicts of interest that are directly relevant to this article.

\section{References}

1. Garattini, L., Padula, A.: Competition in pharmaceuticals: more product-than price-oriented? Eur. J. Health Econ. 19(1), 1-4 (2018)

2. Garattini, L., Curto, A., Freemantle, N.: Pharmaceutical price schemes in Europe: time for a 'continental' one? Pharmacoeconomics 34(5), 423-426 (2016)

3. Garattini, L., Padula, A.: Between pharmaceutical patents and European patients: is a compromise still possible? Expert Opin. Ther. Pat. 27(10), 1073-1076 (2017)

4. Garattini, L., Cornago, D., De Compadri, P.: Pricing and reimbursement of in-patent drugs in seven European countries: a comparative analysis. Health Policy 82(3), 330-339 (2007)

5. Garattini, L., Casadei, G.: Health technology assessment: for whom the bell tolls? Eur. J. Health Econ. 9(4), 311-312 (2008)

6. Garattini, L., Padula, A.: Dutch guidelines for economic evaluation: 'from good to better' in theory but further away from pharmaceuticals in practice? J. R. Soc. Med. 110(3), 98-103 (2017)

7. Brooks, E., Geyer, R.: Can a medical need clause help manage the growing costs of prescription drugs in the EU? Health Econ. Policy Law 11(2), 179-192 (2016)
8. Curto, S., Ghislandi, S., van de Vooren, K., Duranti, S., Garattini, L.: Regional tenders on biosimilars in Italy: an empirical analysis of awarded prices. Health Policy 116(2), 182-187 (2014)

9. Van der Gronde, T.V., Uyl-de Groot, C.A., Pieters, T.: Addressing the challenge of high-priced prescription drugs in the era of precision medicine: a systematic review of drug life cycles, therapeutic drug markets and regulatory frameworks. PLoS One 12(8), e0182613 (2017)

10. Garattini, L., Curto, A.: Performance-based agreements in Italy: 'Trendy Outcomes' or Mere illusions? Pharmacoeconomics 34(10), 967-969 (2016)

11. Garattini, L., Curto, A., Padula, A.: Reimbursable drug classes and ceilings in Italy: why not only one? Eur. J. Health Econ. 17(8), 923-926 (2016)

12. Garattini, L., Padula, A.: 'Appropriateness' in Italy: a 'Magic Word' in pharmaceuticals? Appl. Health Econ. Health Policy 15(1), 1-3 (2017)

13. van de Vooren, K., Curto, A., Garattini, L.: Optional copayments on anti-cancer drugs. BMJ 346, f349 (2013)

14. Frakt, A.B., Chernew, M.E.: The importance of relative prices in health care spending. JAMA 319(5), 441-442 (2018)

15. Reinhardt, U.: Probing our moral values in health care: the pricing of specialty drugs. JAMA 314(10), 981-982 (2015)

16. Levy, M., Rizansky, N.A.: The pricing of breakthrough drugs: theory and policy implications. PLoS One 9(11), e113894 (2014)

17. Wirtz, V.J., Hogerzeil, H.V., Gray, A.L., Bigdeli, M., de Joncheere, C.P., Ewen, M.A., et al.: Essential medicines for universal health coverage. Lancet 389(10067), 403-476 (2016)

18. Moors, E.H., Cohen, A.F., Schellekens, H.: Towards a sustainable system of drug development. Drug Discov Today 19(11), 1711-1720 (2014)

19. Prasad, V., Mailankody, S.: Research and development spending to bring a single cancer drug to market and revenues after approval. JAMA Intern Med 177(11), 1569-1575 (2017)

20. Lexchin, J.: The relation between promotional spending on drugs and their therapeutic gain: a cohort analysis. CMAJ Open 5(3), E724-E728 (2017)

21. Chandra, A., Garthwaite, C.: The economics of indication-based drug pricing. N. Engl. J. Med. 377(2), 103-106 (2017)

22. Dolgin, E.: Bringing down the cost of cancer treatment. Nature 555(7695), S26-S29 (2018)

23. Gagnon, M.A., Volesky, K.D.: Merger mania: mergers and acquisitions in the generic drug sector from 1995 to 2016. Glob. Health 13(1), 62 (2017)

24. Garattini, L., Curto, A.: European medicines agency: leave the UK but remain the same? JRSM 109(9):324-325 (2016)

25. Garattini, L., Curto, A., Padula, A.: The puzzle of drug delivery in Italy: who wins? Expert Rev. Pharmacoecon. Outcomes Res. 16(3), 331-332 (2016)

26. Ploumen, L., Schippers, E.: Better life through medicine-let's leave no one behind. Lancet 389(10067), 339-341 (2017) 